\title{
Landelijke studie naar competenties van opleiders kindergeneeskunde en hun functie als rolmodel
}

\author{
G. Shabo, H. van der Wijngaart, S. Sana, A.J. Scherpbier, R.J.B.J. Gemke
}

\begin{abstract}
Samenvatting
Achtergrond: Rolmodellen spelen een cruciale rol bij de ontwikkeling van competenties gedurende de opleiding tot specialist. Er is echter weinig bekend over de eigenschappen van rolmodellen die van belang zijn en welke veranderingen in de waardering ervan kunnen ontstaan in het verloop van de opleiding. Het doel van deze studie was gericht op het identificeren van de kenmerken van excellente rolmodellen die artsen in opleiding tot specialist (aios) van belang vinden en vast te stellen of deze eigenschappen aanwezig zijn bij de opleiders in de vervolgopleiding tot kinderarts. Ook werden de eventuele verschillen in opvatting tussen eerste- en vijfdejaars aios geëvalueerd.
\end{abstract}

Methode: Op basis van eerdere literatuurstudies werd een vragenlijst ontwikkeld waarin 27 eigenschappen van rolmodellen waren opgenomen. De items werden gegroepeerd in vijf domeinen (karakter, vaardigheden als clinicus, vaardigheden als docent, vaardigheden als onderzoeker en overige) en werden door de aios gescoord op een vijfpunts Likertschaal, variërend van niet belangrijk (1) tot heel belangrijk (5).

Resultaten: De vragenlijst werd afgenomen onder eerstejaars $(n=44)$ en vijfdejaars $(n=46)$ aios kindergeneeskunde tijdens het per jaargroep landelijk georganiseerde en verplichte onderwijsweekend dat jaarlijks gehouden wordt. In alle domeinen werd de relevantie van de eigenschappen van rolmodellen significant hoger gescoord dan de daadwerkelijke aanwezigheid daarvan, zowel bij eerste- als bij vijfdejaars aios. Eerstejaars aios gaven een hogere score voor de relevantie van alle items in vergelijking met vijfdejaars aios, en deze verschillen waren significant in de domeinen 'vaardigheden als docent' en 'vaardigheden als onderzoeker'. Tussen beide groepen was geen scoreverschil wat betreft het belang van het domein 'vaardigheden als clinicus'.

Discussie en conclusie: Bewustwording van de kenmerken die van belang zijn voor de functie als rolmodel, alsmede de veranderingen die hierin (kunnen) optreden gedurende de opleiding tot medisch specialist werden als relevant aangemerkt. Kenmerken van excellente rolmodellen kunnen veelal worden aangeleerd en ontwikkeld; (h)erkenning daarvan kan bijdragen aan het optimaliseren van de opleiding van toekomstige artsen. (Shabo G, Wijngaart $H$ van der, Sana S, Scherpbier AJ, Gemke RJBJ. Landelijke studie naar competenties van opleiders kindergeneeskunde en hun functie als rolmodel. Tijdschrift voor Medisch Onderwijs 2010;29(4):237-244.)

\section{Achtergrond}

Historisch vormt het verwerven van kennis en ervaring de hoeksteen van de opleiding tot medisch specialist. In verschillende landen werden de laatste jaren gekenmerkt door een herziening van de opleiding tot medisch specialist, met als doel de ontwikkelingen in de medische technologie en veranderende behoeften in onze samenleving beter tot hun recht te laten komen. Meerdere innovatieve kaders zijn hiervoor ontwikkeld. Het be- 
kendste voorbeeld is het zogenoemde 'CanMEDS' systeem (Canadian Medical Education Directives for Specialists) bestaande uit zeven rollen: medisch expert (als de centrale rol), communicator, medewerker, gezondheidbevorderaar, manager, academicus en professional. ${ }^{1}$ Dit CanMEDS model voor medische competenties is in meerdere landen waar gewerkt werd aan het vernieuwen van de opleiding tot medisch specialist, waaronder Nederland, overgenomen. Ook het belang van nader onderzoek naar de competenties van de opleidersgroep is onderkend, zoals blijkt uit recent verschenen Nederlandse publicaties. ${ }^{2-3}$

Bij het ontwikkelen van competenties gedurende de medische (vervolg)opleiding is de invloed van rolmodellen groot. ${ }^{4}$ Rolmodellen worden gedefinieerd als artsen die een leerling zou willen imiteren in hun doen en wezen als professionals. ${ }^{3}$ Meerdere studies in het verleden hebben aangetoond dat rolmodellen een belangrijke factor zijn bij het beïnvloeden van waarden, attitudes, gedrag en ethiek van artsen in opleiding tot specialist (aios). ${ }^{4-5}$ In meerdere publicaties is gerapporteerd over inzichten in kenmerken en eigenschappen van excellente rolmodellen.6-8

In deze onderzoeken binnen de medische basisopleiding werd vastgesteld dat studenten geneeskunde items als persoonlijke kwaliteiten, vaardigheden als docent en klinische bekwaamheid als kernvariabelen beschouwen in de (h)erkenning van rolmodellen. ${ }^{6-8}$ Er is echter weinig onderzoek gedaan naar de relatieve waardering van deze determinanten in de medische vervolgopleiding, terwijl deze informatie nuttige en belangrijke inzichten kan verschaffen en mogelijk kan bijdragen aan het ontwikkelen van systemen om de opleidingskwaliteit te verbeteren (bijvoorbeeld na- en bijscholing van leden van de opleidersgroep en het opstellen van pro- fielschetsen voor te werven nieuwe (staf) leden). Eerdere studies hebben laten zien dat men eigenschappen van rolmodellen kan verwerven en ontwikkelen ${ }^{4}$ maar er was weinig bekend over de mogelijke veranderingen in de gradatie van waardering van specifieke eigenschappen door aios gedurende de voortgang van de opleiding.

Het doel van deze studie was 1) het identificeren van relevante eigenschappen van excellente rolmodellen en de ervaren aanwezigheid van deze eigenschappen bij opleiders in de medische vervolgopleiding (waarbij als opleider iedere specialist in het team wordt beschouwd die betrokken is bij het opleiden van de aios) en 2) het ontdekken van verschillen in de waardering van de determinanten van rolmodellen tussen eerste- en vijfdejaars aios kindergeneeskunde.

\section{Methode}

De studie werd uitgevoerd tijdens het jaarlijkse per jaargroep landelijk georganiseerde, verplichte onderwijsweekend voor aios kindergeneeskunde. Hierbij werd gebruik gemaakt van een enquête bestaande uit 27 items, die ontwikkeld was op basis van gegevens uit eerdere studies over excellente rolmodellen. ${ }^{5-69}$ De enquête werd naar het Nederlands vertaald volgens standaardvertaalprocedures. ${ }^{10}$ De items werden ingedeeld in vijf domeinen: karakter (8), vaardigheden als clinicus (7), vaardigheden als docent (7), vaardigheden als onderzoeker (4) en overige (1) - zie Box 1. De interne consistentie werd bepaald met Cronbach's alpha met een drempelwaarde van 0.70 . De respondenten, een nationaal cohort van eerstejaars $(n=44)$ en vijfdejaars $(n=46)$ aios kindergeneeskunde, werd gevraagd om de relevantie van deze items te waarderen op een vijfpunts Likertschaal, variërend van niet belangrijk (1) tot heel belangrijk (5). Een aios kindergeneeskunde werd als eerstejaars be- 
schouwd wanneer hij of zij in de laatste 12 maanden was begonnen aan de opleiding. Een aios kindergeneeskunde werd als vijfdejaars beschouwd wanneer hij of zij tussen 48 en 60 maanden geleden was begonnen aan de opleiding. De aios werd gevraagd om, naast het graderen van de relevantie, op dezelfde vragenlijst ook een score toe te kennen aan de daadwerkelijke aanwezigheid van deze items bij hun directe supervisoren gedurende de laatste twee maanden. De vijfpunts Likertschaal varieerde van afwezig (1) tot evident aanwezig (5). De vragenlijst werd anoniem af-

Box 1. Vragenlijst Betekenis van rolmodellen in de medische vervolgopleiding kindergeneeskunde.

\section{Code* Item}

1. K1 Heeft een positieve houding ten opzichte van studenten en (co)assistenten

2. K2 Respect voor en (h)erkenning van de rol van niet-medische zorgverleners

3. K3 Is sterk gericht op hoge kwaliteit van patiëntenzorg

4. K4 Is primair gecommitteerd aan het belang c.q. perspectief van de patiënt

5. K5 Heeft goed contact met andere zorgverleners

6. K6 Is eerlijk en integer

7. K7 Ziet er verzorgd en representatief uit

8. K8 Toont interesse in andere dan medische onderwerpen

9. C1 Is zeer goed in klinisch redeneren

10. C2 Is een excellente diagnosticus

11. C3 Maakt een professionele indruk

12. C4 Leert (ouders van) patiënten veel over hun ziekte

13. C5 Communiceert goed met (ouders van) de patiënt

14. C6 Informeert (ouders van) patiënten volledig

15. C7 Toont empathie voor (ouders van) patiënten

16. D1 Heeft geduld

17. D2 Stimuleert en daagt uit tot leren op de werkplek

18. D3 Begrijpt leer- en kennisbehoefte van studenten, co's, aios

19. D4 Communiceert effectief en efficiënt met studenten, co's en aios

20. D5 Legt complexe dingen goed en begrijpelijk uit

21. D6 Toont enthousiasme voor onderwijs en opleidingsactiviteiten

22. D7 Speelt goed in op het uiteenlopende niveau van voorkennis van studenten, co's, aios

23. 01 Heeft veel wetenschappelijke publicaties

24. O2 Stimuleert interesse in en deelname aan wetenschappelijk onderzoek

25. $\mathrm{O} 3$ Is bij voordrachten frequent passief en actief aanwezig

26. $\mathrm{O} 4$ Heeft grote kwaliteiten bij voordrachten en presentaties

27. R Neemt deel aan (niet medische) sociaal-maatschappelijke activiteiten

${ }^{*} \mathrm{~K}=$ Karakter

$C=$ Vaardigheden als clinicus

$\mathrm{D}=$ Vaardigheden als docent

$\mathrm{O}=$ Vaardigheden als onderzoeker

$\mathrm{R}=$ Rest (overige) 
genomen en vertrouwelijkheid van de gegevens werd gewaarborgd. De gemiddelde score voor elk item van de 27 items werd berekend evenals het geaggregeerde gemiddelde voor elk domein. De relevantie en de daadwerkelijke aanwezigheid van de items werden met elkaar vergeleken, als ook de verschillen tussen eerste- en vijfdejaars aios, zowel per item als per domein. De significantie $(\mathrm{p}<0.05)$ van de verschillen werd berekend door middel van een t-toets (met Bonferroni correctie).

\section{Resultaten}

De vragenlijst werd door alle aios kindergeneeskunde, 44 eerstejaars en 46 vijfdejaars, ingevuld (100\% respons). De Cronbach's alpha's van de domeinen waren als volgt: karakter 0.78 , vaardigheden als clinicus 0.74 , vaardigheden als docent 0.88 en vaardigheden als onderzoeker 0.78. Het vijfde domein 'overige' bestond uit slechts één item, wat een bepaling van de Cronbach's alpha onmogelijk maakte. Van elk van de 27 items van de vragenlijst werd een gemiddelde berekend voor eerste- en vijfdejaars aios kindergeneeskunde. Dit werd apart gedaan voor respectievelijk de relevantie en de werkelijke aanwezigheid van deze items.

Tabel 1 geeft de verschillen tussen eerste- en vijfdejaars aios weer wat betreft de aangegeven relevantie van de verschillende eigenschappen. Voor eerstejaars aios kindergeneeskunde was het domein vaardigheden als docent het belangrijkste en waren de vaardigheden als onderzoeker van relatief beperkt belang. Voor vijfdejaars aios kindergeneeskunde was het domein vaardigheden als clinicus het belangrijkste en vonden zij, evenals de eerstejaars aios, de vaardigheden als onderzoeker van relatief beperkte relevantie. Ten opzichte van vijfdejaars aios scoorden derdejaars aios de domeinen vaardigheden als docent en vaardigheden als onderzoeker significant hoger (respectievelijk $\mathrm{p}<0.01$ en $\mathrm{p}<0.01$ ) en gaven zij ook hogere scores wat betreft de wenselijkheid van alle items, maar deze verschillen waren niet significant.

Tabel 2 en tabel 3 tonen de verschillen tussen de relevantie en de ervaren aanwezigheid van alle vijf domeinen. In alle domeinen gaven zowel de eerste- als vijfdejaars aios kindergeneeskunde significant hogere scores voor de relevantie dan voor de door hen ervaren aanwezigheid van deze eigenschappen van rolmodellen; in het bijzonder betrof dit het domein vaardigheden als docent.

\section{Discussie}

Deze studie laat zien dat beginnende aios kindergeneeskunde hogere scores geven voor de relevantie van eigenschappen van rolmodellen dan senior aios, met significante verschillen voor de domeinen vaar-

Tabel 1. Relevantie van verschillende eigenschappen van rolmodellen voor aios kindergeneeskunde.

\begin{tabular}{lccccc}
\hline & \multicolumn{2}{c}{ Eerstejaars } & \multicolumn{2}{c}{ Vijfdejaars } \\
\hline Domein & Gemiddelde & SD* & Gemiddelde & SD* & p-waarde \\
\hline Karakter & 4.4 & 0.6 & 4.3 & 0.6 & 0.18 \\
Vaardigheden als clinicus & 4.5 & 0.6 & 4.4 & 0.6 & 0.28 \\
Vaardigheden als docent & 4.6 & 0.6 & 4.3 & 0.6 & $<0.01$ \\
Vaardigheden als onderzoeker & 3.9 & 0.8 & 3.6 & 0.7 & $<0.01$ \\
Overige & 3.5 & 1.2 & 3.2 & 0.9 & 0.23 \\
\hline
\end{tabular}

*Standaarddeviatie 
Tabel 2. Scores van eerstejaars aios kindergeneeskunde.

\begin{tabular}{lcccccc}
\hline & \multicolumn{2}{c}{ Relevantie } & \multicolumn{2}{c}{$\begin{array}{c}\text { Ervaren } \\
\text { aanwezigheid }\end{array}$} \\
\hline Domein & Gemiddelde & SD* $^{*}$ & Gemiddelde & SD* $^{*}$ & Verschil & p-waarde \\
\hline Karakter & 4.4 & 0.6 & 3.8 & 0.9 & 0.6 & $<0.01$ \\
Vaardigheden als clinicus & 4.5 & 0.6 & 3.9 & 0.9 & 0.6 & $<0.01$ \\
Vaardigheden als docent & 4.6 & 0.6 & 3.7 & 1.0 & 0.9 & $<0.01$ \\
Vaardigheden als onderzoeker & 3.9 & 0.8 & 3.6 & 1.1 & 0.3 & 0.02 \\
Overige & 3.5 & 1.2 & 3.2 & 0.9 & 0.3 & 0.03 \\
\hline
\end{tabular}

* Standaarddeviatie

Tabel 3. Scores van vijfdejaars aios kindergeneeskunde.

\begin{tabular}{lcccccc}
\hline \multicolumn{2}{c}{ Relevantie } & \multicolumn{2}{c}{$\begin{array}{c}\text { Ervaren } \\
\text { aanwezigheid }\end{array}$} \\
\hline Domein & Gemiddelde & SD* $^{*}$ & Gemiddelde & SD* & Verschil & p-waarde \\
\hline Karakter & 4.3 & 0.6 & 3.7 & 0.9 & 0.6 & $<0.01$ \\
Vaardigheden als clinicus & 4.4 & 0.6 & 3.8 & 0.8 & 0.6 & $<0.01$ \\
Vaardigheden als docent & 4.3 & 0.6 & 3.3 & 1.0 & 1.0 & $<0.01$ \\
Vaardigheden als onderzoeker & 3.6 & 0.7 & 3.0 & 1.0 & 0.6 & $<0.01$ \\
Overige & 3.2 & 0.9 & 3.0 & 0.9 & 0.2 & $<0.05$ \\
\hline
\end{tabular}

* Standaarddeviatie

digheden als docent en vaardigheden als onderzoeker. Bij beide groepen aios was er bovendien een significant verschil tussen de aangegeven relevantie en de daadwerkelijke aanwezigheid van de eigenschappen van rolmodellen bij de supervisoren van hun meest recente stage.

De hogere scores in de groep van eerstejaars aios ten opzichte van de vijfdejaars voor wat betreft de relevantie van alle domeinen zou verklaard kunnen worden door het feit dat de vijfdejaars aios meer ervaren zijn. Hierdoor zouden zij meer kritisch kunnen zijn ten aanzien van de kwaliteiten van hun begeleiders en wellicht ook beter in staat zijn de eigenschappen van hun supervisoren te beoordelen.

Belangrijk en interessant is de bevinding dat eerstejaars aios kindergeneeskunde andere leerbehoeften (b)lijken te hebben in vergelijking met vijfdejaars aios. Eerstejaars hebben de behoefte aan het verkrijgen van veel nieuwe informatie en verscheidene nieuwe vaardigheden in een korte periode. Dit zou de verklaring kunnen zijn voor het feit dat bij hen het domein vaardigheden als docent het hoogste scoort. Blijkbaar is het voor hen belangrijk dat rolmodellen in staat zijn veel onderwerpen op een constructieve en niet intimiderende wijze uit te leggen. Vijfdejaars aios kindergeneeskunde, die zich reeds vele competenties eigen hebben gemaakt, vinden de onderwijskwaliteiten van hun supervisor relatief minder belangrijk. Niettemin blijven zij de vaardigheden van hun rolmodellen als clinici van groot belang vinden. Zoals Prideaux et al. hebben gezegd zouden wij kunnen stellen dat een goed rolmodel goed dient te zijn in het ondernemen, demonstreren en uitleggen van het handelen. ${ }^{11}$

Voor beide groepen aios was het domein vaardigheden als onderzoeker van 
relatief weinig belang. Toch was er een significant verschil tussen de beide groepen, hetgeen een afname van het belang van vaardigheden als onderzoekers met het vorderen van de opleiding zou kunnen suggereren, zoals ook in eerdere studies reeds aangetoond is. Blijkbaar zoeken aios in hun rolmodel naar eigenschappen die zij in hun dagelijkse praktijk kunnen gebruiken. Voor de meeste aios is degene die zij als hun rolmodel beschouwen niet hun onderzoekspartner. Het feit dat de vaardigheden als onderzoeker als de minst belangrijke lijken te worden beoordeeld is nogal opmerkelijk.

De vastgestelde discrepantie tussen de aangegeven relevantie en de daadwerkelijke aanwezigheid van componenten van excellente rolmodellen komen overeen met de bevindingen van Wright et al. van meer dan een decennium geleden; dit ondanks de toegenomen aandacht voor deze discrepantie en de herzieningen binnen de vervolgopleidingen. ${ }^{6}$ Het is evident dat dit een belangrijk aandachtspunt is voor opleiders, afdelingshoofden en beleidsmakers van UMC's en algemene opleidingsziekenhuizen.

Het leren van rolmodellen vindt plaats door observatie en reflectie, en is een complex mengsel van bewuste en onbewuste activiteiten. Actieve reflectie op de klinische praktijk kan onbewuste gevoelens omzetten in bewuste gevoelens met een vertaling naar gedrag. ${ }^{12}$ Het goede nieuws is dat meerdere studies reeds hebben aangetoond dat specifieke componenten van excellente rolmodellen gerelateerd zijn aan gedrag dat aanpasbaar en verwerfbaar is. Cruess et al. hebben in een uitstekend review suggesties gepubliceerd over strategieën om het gedrag als rolmodel te verbeteren. ${ }^{12}$ De hoofdpunten hiervan zijn a) het bewustzijn van de medische specialist van zijn/haar functie als rolmodel, b) het demonstreren van goede klinische capaciteiten in alle competenties die nodig zijn om een excellente arts te zijn en c) de eigenschap om tijd te nemen voor onderwijs en opleiden. Individuele stafleden kunnen door middel van dit en vergelijkbaar onderzoek hierin een beter inzicht krijgen.

Daarnaast dient de rol van opleidingsziekenhuizen niet te worden onderschat. Deze zouden een klimaat moeten creëren waarin rolmodellen voor de opleiding kunnen excelleren. Dit kan bijvoorbeeld worden bereikt door het aanmoedigen van een cultuur van kritische zelfreflectie en door meer inspanningen voor het verbeteren van de functie van rolmodellen. In de UMC's ligt het primaat (te?) sterk bij de ontwikkeling van de rol als onderzoeker. Ondanks substantiële inspanningen dient dit nog steeds beter in balans te worden gebracht met de ontwikkeling van excellente rolmodellen voor onderwijs en opleiding in de UMC's. Het aanbieden van mogelijkheden aan de medische stafleden om te participeren in cursussen kan hen helpen om een beter rolmodel te worden, en het ontwikkelen van tenure tracks voor talentvolle artsen in het klinisch onderwijs kan daarvan een onderdeel zijn. De huidige studie, samen met eerdere publicaties over dit onderwerp, helpt bij de bewustwording van het grote belang om toekomstige specialisten te leren hoe zij voor toekomstige generaties excellente rolmodellen kunnen worden.

Onze studie heeft een aantal beperkingen. Ten eerste was het aantal deelnemers tamelijk klein en was de onderzoeksgroep beperkt tot één specialisme. Dit betekent dat daarmee de generaliseerbaarheid beperkingen heeft. Maar ook zou het met een grotere groep waarschijnlijk onmogelijk zijn geweest meer significante verschillen aan te tonen. Ten tweede gaf de opzet van de vragenlijst de deelnemers niet de mogelijkheid om aan de attributen 
van excellente rolmodellen een rangorde toe te kennen waardoor met name de relevantie van de te beoordelen eigenschappen niet werd ingeperkt. Tenslotte heeft het studieontwerp de intrinsieke beperkingen van een observationele studie. Wij hebben in deze studie gebruik gemaakt van twee cohorten; een derde cohort, bijvoorbeeld derdejaars aios, had wellicht de getrokken conclusies sterker kunnen maken door een trend te laten zien.

In toekomstige studies willen wij ook medische supervisoren als respondenten includeren met het verzoek aan te geven hoe zij componenten van excellente rolmodellen bij zichzelf en bij hun collegae beoordelen. Daarnaast is het ook zeer interessant om de huidige groep aios kindergeneeskunde te vergelijken met aios van andere specialismen.

\section{Conclusie}

Wij concluderen dat er ruimte is voor verbetering met betrekking tot vrijwel alle attributen van excellente rolmodellering. Belangrijk is dat opleiders zich bewust zijn van de verschuiving van het belang van specifieke componenten van excellente rolmodellen gedurende de voortgang van de medische vervolgopleiding en de consequenties hiervan voor de begeleiding van junior respectievelijk senior aios. Het is evident dat het verwerven van componenten van excellente rolmodellen benadrukt dient te worden in het proces van verbetering van de kwaliteit van de medische vervolgopleiding. Naar verwachting zal dit bijdragen aan het optimaliseren van de opleiding van toekomstige artsen.

\section{Literatuur}

1. Frank JR, Langer B. Skills for the new millennium: report of the societal needs Working Group, CanMEDS 200 Project. Ann R Coll Physicians Surg Can 1996;29:206-16.
2. Boor K, Teunissen PW, Scherpbier AJ, van der Vleuten CP, van de Lande J, Scheele F. Residents' perceptions of the ideal clinical teacher--a qualitative study. Eur J Obstet Gynecol Reprod Biol 2008 Oct;140(2):152-7. Epub 2008 May 2. PubMed PMID: 18455863.

3. Lombarts MJ, Arah OA, Busch OR, Heineman MJ. Meten en verbeteren van opleiderskwaliteiten van klinische opleidersmet het SETQ system. Ned Tijdschr Geneeskd 2010 Feb 20;154(7):A1222. Dutch. PubMed PMID: 20170574. [Using the SETQ system to measure and improve clinical teachers' reaching skills. Dutch Medical Journal 2010 Feb 20:154(7): A 122].

4. Wright S, Carrese JA. Excellence in role modelling: insight and perspectives from the pros. CMAJ 2002; 167:638-43.

5. Cote L, Leclere H: How clinical teachers perceive the doctor-patient relationship and themselves as role models. Acad Med 2000;75:1117-24.

6. Wright S, Kern DE, Kolodner K, Howard DM, Brancati FL. Attributes of excellent attendingphysician role models. The New England Journal of Medicine 1998;1986-93.

7. Wright S, Wong A, Nevill C. The impact of role models on medical students. JGIM 1997;12:53-56.

8. Wright S. Examining what residents look for in their models. Acad Med 1996;71:290-292.

9. Elzubeir MA, Rizk DEE. Identifying characteristics that students, interns and residents look for in their role models. Med Educ 2001; 35:272-277.

10. Guillemin F, Bombardier C, Beaton D. Cross cultural validation of health realted quality of life maesures. Literature review and proposed guidelines. J Clin Epidemiol Dec 1993;46(12):1417-32.

11. Prideaux D, Alexander H, Bower A, Dacre J, Haist S, Jolly B, Norcini J, Roberts T, Rothman A, Rowe R, Tallett S. Clinical teaching: maintaining an educational role for doctors in the new health care environment. Med Educ 2000;34:820-826.

12. Cruess SR, Cruess RL, Steinert Y. Role modellingmaking the most of a powerful teaching strategy. BMJ 2008;336: 718-721.

De auteurs:

Drs. G. Shabo is aios kindergeneeskunde.*

Drs. H. van der Wijngaart is student geneeskunde.*

Drs. S. Sana is student geneeskunde.*

Prof. dr. A.J. Scherpbier is hoogleraar kwaliteitsbevordering onderwijs geneeskunde, instituut voor medisch onderwijs, Universiteit van Maastricht.

Prof. dr. R.J.B.J Gemke is kinderarts en opleider. *

* Allen werkzaam in het VU Medisch Centrum, Amsterdam. 
Correspondentieadres:

Drs. G. Shabo, afdeling kindergeneeskunde, VU Medisch Centrum, postbus 7057, 1007 MB Amsterdam. Tel.:020-4443319; e-mail: g.shabo@vumc.nl
Belangenconflict: geen gemeld

Financiële ondersteuning: geen gemeld

\section{Summary}

Background: Role models are regarded as pivotal for the development of competencies during postgraduate speciality training, but little is known about the relevant elements of effective role models, and potential changes therein with the advancement of speciality training. The objective of this study was to identify characteristics of excellent role models and their presence in speciality training and to examine differences with regard to these aspects between junior (first year) and senior (fifth year) postgraduate trainees.

Method: Based on previous studies we developed a questionnaire asking respondents to rate the importance of 27 attributes of role models on a five-point Likert scale (1=unimportant; $5=$ very important). The items were grouped into five categories: personality, clinical skills, teaching skills, research skills and others.

Results: The respondents were national cohorts of junior $(n=44)$ and senior $(n=46)$ postgraduate trainees, in their first and fifth year of postgraduate training, respectively. In all categories junior and senior trainees' ratings of the relevance of the attributes of role models were significantly higher than the ratings of their actual presence. The junior trainees' relevance ratings were higher than those of the senior trainees, with significant differences for 'teaching skills' and 'research skills' and no difference for 'clinical skills'.

Discussion and conclusion: It is important for teachers to be aware of what trainees consider to be important attributes of excellent role models and how trainees' views change over the course of their training. Since attributes of excellent role models are related to behaviours that can be modified and learned, awareness thereof can be helpful in optimising the learning process of future physicians. (Shabo G, Van der Wijngaart H, Sana1 S, Scherpbier AJ, Gemke RJBJ. National study among Dutch paediatric trainees to examine supervisors' competencies and aspects of good role modelling. Netherlands Journal of Medical Education 2010;29(4)237-244.) 